\title{
MAXIMIZING LIBRARY PRESENCE WHILE MINIMIZING ONLINE MAINTENANCE
}

\author{
Peggy Lynn MacIsaac \\ Athabasca University, 1 University Drive, Athabasca Alberta, Canada T9S 3A3 \\ macisaac@athabascau.ca
}

\begin{abstract}
Keywords: Course management systems, e-learning, electronic resource pages, information literacy, learning management systems, librarians, libraries, library \& the Internet, LibX toolbar, LMS, Moodle.

Abstract: $\quad$ This paper presents challenges and opportunities for an academic library to increasing its presence in an online learning management system (LMS). Successful examples from Athabasca University, Canada's Open University will highlight the benefits of a collaborative team approach to course development and LMS software applications. This case study demonstrates how an academic library can participate fully as an active partner in the learning process. Specific focus is given to the seamless access for students from the LMS to licensed electronic resources.
\end{abstract}

\section{INTRODUCTION}

In this time of rapid development of web pages, email, instant messaging, online tutorials, chat, RSS feeds, blogs, tag clouding, Facebook profiles, YouTube videos and Second Life avatars, academic libraries are challenged to create a multi-faceted online presence of their own. In addition, as courses increasingly occur online rather than in classrooms, academic libraries have an opportunity to connect with students through a learning management system (LMS). Presenting digital library resources to students is a Sisyphean task of content management. The balance of developing new online initiatives while maintaining accurate content is a constant struggle. This paper explores how Athabasca University Library in Alberta, Canada, has addressed these challenges.

\subsection{Athabasca University Library}

Athabasca University (AU) is Canada's Open University, serving 38,000 (or approximately 7,300 full-load equivalent) undergraduate, master and doctoral students at a distance around the world since 1970 (Athabasca University, 2010). One course delivery model used at AU is Moodle, ${ }^{1}$ an online learning management system. Some other universities using Moodle have subject librarians embedded in the online courses to provide timely and relevant library related information. This may be a good fit in larger university libraries, which are restructuring their reference services delivery models due to a decrease of in-person queries and an increased demand for remote services (ThomsettScott \& Reese, 2006). At AU Library there are no subject specialists; the public service librarians work as a team of generalists. Nearly all reference and information literacy services are delivered at a distance. To have a current librarian embedded in each of the hundreds of AU online courses would be an insurmountable challenge.

\section{ACADEMIC DIGITAL MILIEU}

\subsection{Digital Seamlessness}

Eales and Scantlebury, writing about Britain's Open University, have said that "for Open University students the Library website is the Library, since most will never visit the physical Library building" (2007, p. 36). This concept can be extrapolated to say that separating the virtual library from the online classroom would replicate a structural relic from centuries of post-secondary education delivered in discrete stone and mortar buildings. Makri, Blandford, Gow, Rimmer, Warwick and Buchannan (2007) applied decades of research on mental mapping theory and digital library services usability to their study of the digital 
information seeking behaviour of graduate students. Their research shows that people using digital library resources relied more on their understanding of other digital systems such as Google than on metaphors and analogies to the traditional library ( $\mathrm{p}$. 435). In their online lifestyles, students have come to expect instant gratification when seeking answers online, and this leads to an expectation that full text resources for e-courses are effortlessly available any time of the day or night.

Much of the literature on library participation in learning management systems shows that there is a common objective among libraries to deliver resources seamlessly within the LMS (Eales and Scantlebury, 2007; Ge, 2010; Henk, 2010; Jamtsho \& Bullen, 2007; Luther, 1998). This goal is sometimes in conflict with a librarian's desire to build information literacy skills among students. Often, librarians are asked to balance between providing desktop delivery of full text sources and teaching students to find material.

One way to think through this decision is to ask, "What is the most important learning outcome?" If the answer is to have the student recognize a journal article citation and learn how to find the full text, then providing direct links within the courseware is counterproductive. If it is more important to read and respond to the journal articles, then providing full text links keeps the student focused and lessens the tangential task of searching. It is clear that online learning, delivered anytime and anywhere, shifts the pedagogical focus to be student centred (Black \& Blankenship, 2010, p. 466; Boumarafi, 2010, p. 277; Carlson \& Everett, 2000, p. 9). This requires libraries to shift their service model to deliver content within the student's digital communities. Internet technologies are leading the redefinition of the traditional domains of libraries and classrooms.

\subsection{Learning Management Systems and Libraries}

The notion of LMS started to be debated in the literature around the mid-1990s (Boumarafi 2010, p. 277). According to Dunn \& Menchaca, by 2003 " $94 \%$ of U.S. colleges and universities had implemented some form of LMS" (2010, p. 473). Colleges and universities are increasingly using LMS software to deliver courses for distance education and in blended learning, where the online course supplements the face-to-face classroom experience. Discussions on how to choose an LMS and the arguments for selecting Moodle are best addressed by other authors. (See Appleton, DeGroot, Lampe, \& Carruthers, 2009; Carlson \& Everett, 2000; Jensen, 2010; Maikish, 2006; Menges, 2009.)
Other widely used LMSs include Blackboard and WebCT, which have now merged, ${ }^{2}$ Desire2Learn ${ }^{3}$ and Sakai. ${ }^{4}$ Moodle is currently used at Athabasca University, and the number of AU courses delivered through Moodle is increasing. Many of the colleges and universities using Moodle find it flexible and use it to deliver a variety of instructional services through learning modules, discussion forums, quizzes, and a variety of applications constantly being developed by the open source community of users (Eales \& Scantlebury, 2007; Najduch, 2009). The power of any LMS is the interconnectivity of students, faculty and librarians to share resources, information and ideas.

Black wrote in 2008 that the value of having a library presence in a learning management system is undisputed (p.496). There are various taxonomies of roles that libraries can fulfil in the selection, development and utilization of LMSs. Shank and Dewald describe these in terms of macro and micro involvement (2003, p. 38). Libraries can provide generic access to resources and virtual reference services at a macro level, or they can develop course-specific embedded initiatives at a micro level. Still others describe a library's role in terms of deliverables. One is to provide access to library resources; the other, information literacy instruction through stand-alone non-credit courses or library tutorials, modules and quizzes built into courses (Karplus, 2006; Smale \& Regalado, 2009). Black points out that electronic reserves and information literacy are the most common library services deployed within learning management systems (2008, p. 497). This paper will elaborate on AU Library examples of each.

While the benefits to creating a library presence within an LMS may be multidimensional, the stated challenges seem consistent. At many universities, faculty members see librarians as playing a minor role in learning design, for example providing links to required readings or to the library homepage (Black 2008, p. 497). Many authors discuss how the library's involvement in the learning management system can enhance overall learning (Date \& Walavalkar, 2009, p. 53; Dunn \& Menchaca, 2010, 470). Inappropriate translation of traditional delivery models into the digital realm can make an online library presence clumsy and boring (Reinhart 2008 , p. 20). The fundamental strength of the online learning environment is that it is interactive. Carlson points out that course materials presented in the digital realm will be read differently than if in print. Carlson suggests breaking e-text into chunks of 100 words or less because approximately $79 \%$ of users scan web pages while only $16 \%$ read them word for word (2000, p. 6). Dunn and Menchaca point out that users on average spend four minutes 
viewing an e-book and eight reading an e-journal (2010, p. 475). There are "significant challenges for library staff in the delivery of prompt quality eservices and content" (Boumarafi 2010, p. 278). Many have written that the difficulties in integrating digital libraries into the e-learning environment have been attributed to software incompatibility between LMSs and tools such as federated searches, citation management, contact management, integrated library systems and authentication.

Black and Blankenship summarize these various challenges well. They wrote, "Students are course centric in their work and the library resources need to be presented to them in that context in a convenient place. At the same time, librarians are faced with increasing demands on their time and resources so these efforts must be scalable" (2010, p. 466).

\subsection{Library and Faculty Collaboration}

In spite of the pervasive use of LMSs in postsecondary education in the United States, Dunn and Menchaca acknowledge that libraries are rarely considered when decisions concerning LMSs are made (2010, p. 473). Of the 27 academic libraries surveyed by Boumarafi in 2010, $86.1 \%$ stated that librarians were not playing any significant role in courseware initiatives (p. 279). Copeland agreed with this conclusion when she wrote: "It is disappointing to see that references to libraries' role in e-learning tend often to be at best superficial" (2006, p. 201). Black concurred, stating that rarely is the library involved in the procurement or management of LMSs (2008, p. 497).

Black and Blankenship highlight successful faculty-library collaborations being borne from a development of common goals for the LMS project (2010, p. 463). A report from the Canadian Association of Research Libraries in 2001 found that when librarians were included in the early stages of course planning, development or redesign, they were able to integrate concepts of information literacy throughout the curriculum. Faculty members responded positively because they realized that librarians have expertise in articulating information needs, finding appropriate information resources online and critically assessing the results of an online search, all of which are key to success in elearning (para. 10). Athabasca University's inclusive model for collaboration in learning is entrenched at many levels. There is a librarian included on most active course development teams, as well as many campus-wide committees addressing web development, writing support and student and frontline services. There is a librarian on the steering committee for the learning management system itself. This approach contributes to thoughtful development of a consistent online library presence (O’Brien \& Wisbey, 2008).

The following three examples show ways that the AU library has been involved in information literacy initiatives:

1. The library co-developed an in-depth online legal studies tutorial that derived its organization from the knowledge structure of the course.

2. The library worked closely with a professor to develop assignments aimed at teaching students how to find, evaluate and synthesize reliable resources on divisive, contentious current issues.

3. A graded library search skills module was built into a for-credit course.

AU Library is engaged in LMS governance, design and development issues.

\section{AU LIBRARY MOODLE}

\subsection{E-reserves}

In 2002, AU Library developed a digital reading room (DRR) for course reserves whose architecture was built and is maintained by AU Library staff members. Each course in the DRR posts its material to its own unique DRR file. With the advent of courses being developed in Moodle, the future use of the DRR was unclear as interconnectivity is a strength of any learning management system. Where available, persistent uniform resource locators (PURLs) are used to link from the DRR to licensed e-journals and e-books. In general, PURLs are more useful than a digital object identifier (DOI) because properly formatted PURLs maintain the authentication information needed for a student to freely access the content to which the library has paid a licensing fee. Searching by a DOI can lead the student to a publisher's fee based access website. When the database JSTOR changed its PURLs recently, the value of maintaining links to required online readings through the DRR was confirmed because those links were updated globally. Direct links to JSTOR from different Moodle courses had to be changed individually. The optimal solution in terms of easy maintenance is to maintain current source links in the DRR.

There are several ways AU Library has achieved good linkage. One is to list the course DRR file as one of the main resources indexed on the homepage of the respective Moodle course. The link directs students to the top of a DRR file to use the navigational tools within the DRR to find the 
reading they seek. Another is to display all the reading citations throughout a Moodle course. Each citation links to the related unit of the course's DRR file. A third way is to create a pass-through link from a citation within the Moodle course through a DRR redirect to the respective full text. For the student, this is the most seamless since the full text displays once the citation is clicked. The added beauty is that the student sees the content displayed within a pop-up window while the Moodle course environment remains in the background easing navigation between the two. Designing simplicity into functionality ensures both technically savvy users and digital novices experience problem-free access through one interface.

\subsection{Library Block}

Many libraries are reaching out to student users where they are spending their time online (Colvin, 2008 , p. 243). The five-year study of undergraduate students by Judd and Kennedy found that the most frequented sites and technologies used were the students' LMS, Google (notably not Google Scholar), email and Facebook (2010, p. 1569). In the Ge study, doctoral students and professors ranked the Web as the most significant computer technology to meet their information seeking needs. The other top five technologies identified were databases, e-journals, library catalogues, and email in descending order (2010, p. 450).

Wanting to increase the library exposure to students, AU Library customized a LibX toolbar, ${ }^{5}$ an Internet browser plug-in that allows students to quickly search a select number of library resources from anywhere on the web. Using the LibX toolbar, students can easily move from reading nonacademic online material to finding relevant scholarly literature. Its design is a clean single-row toolbar with one search box. The Googlization of searching has made the single box an optimal userfriendly search standard.

This clean but robustly functional single search box layout was the design inspiration for the development of the AU Library Moodle block. Knowing that screen real estate is at a premium, it had to be kept concise. One design criteria was to avoid scrolling and the wordiness that tends to lose the students' attention. The library sought to link to a few key portal pages within the AU Library website, presenting a functional search tool as streamlined as the AU Library's LibX toolbar. When the librarian presented the initial design concept, its functionality did not fit the Moodle learning environment. Fortunately, with time and creativity, AU computing services staff developed the coding to allow students to search select AU
Library pages and licensed databases. The library block also contains some static pages.

Both versions of the AU Library Online Public Access Catalogue (OPAC) on the Millennium platform are displayed. The version called Encore, referred to as AU Library Catalogue 2.0 on the AU Library website, has a single keyword search box and provides intuitive click-through features to refine searches. The Web-Pac Pro version has a more robust multi-field, multi-row search capacity for effective and efficient navigating. There is value to AU Library in providing access through two different interfaces to the same collection of catalogue records. It suffices various information seeking needs.

Students can also search some AU Library web pages from the Moodle block. The Journal Title List is for searching for known articles. AU Space is Athabasca University's repository of AU staff and faculty research. The e-books search option is a populated search of the Web-Pac Pro version of the AU Library Catalogue.

Keyword searches are provided to seven general databases which are relevant to all disciplines taught at AU. This search option is not a federated search. A federated search tool can be integrated into future versions of the AU Library Moodle block once AU has finished developing a tool that works well for AU Library resources.

Only three static links are included. One to the AU Library Help Centre providing tips on such topics as the research process, using online tools and citation styles. The second is a link to a list of $\mathrm{AU}$ licensed databases sorted by subject. The third static link is to the library's Contact Us page.

A notable omission is a direct link to the $\mathrm{AU}$ Library homepage. Instead, there is a dynamic search of the AU Library website, which is functionally preferable.

\subsection{Future Research and Developments}

By conducting student usability testing, AU Library could identify how users understand the library services as presented within Moodle courses. This could inform future developments such as tailoring library resources to specific courses and allowing for student modification of library tools. As Black points out, "opportunities will increase as the variety of tools in the toolkit expands" (2008, p. 500). Reinhart aptly describes our current understandings and manifestations of e-learning environments as mere glimpses of the emerging digital classroom $(2008$, p. 25$)$. We have not yet achieved the desired balance of technical efficiency and pedagogical need (Williams van Rooij, 2009, p. 686) in the pursuit of excellence in e-learning. 


\section{CONCLUSION}

AU Library has shown how an academic library can increase its online exposure and minimize maintenance time through thoughtful design. The initiatives described include full participation by the library in course development policy through relevant committees.

The centuries old model of the student walking across campus from the lecture hall to the library to seek information is shifting to a student-centred delivery model where movement from the online course environment to the digital library is seamless. The cross-department team-based approach to course development includes a librarian as a subject matter expert on information literacy skills. This leaves the technical wizardry to those who have a fuller understanding of the software and the creativity to develop and share new applications for the open source learning management system called Moodle. All this contributes to AU Library becoming an active partner in the learning process and significantly enriches the educational experience of AU students through the thoughtful use of library resources.

\section{ACKNOWLEDGEMENTS}

Time to complete this research was provided by Athabasca University Library. Anne LePage, Burke Mortimer, Reg Silvester and Tim Woudstra provided thoughtful critiquing.

\section{REFERENCES}

Appleton, K., DeGroot, D., Lampe, K., \& Carruthers, C. (2009). How rural school libraries stay connected, School Library Monthly, 26(2), 14-16.

Athabasca University. (2010). Athabasca University at a glance. Retrieved from http:// www2.athabascau.ca/aboutau/glance.php

Black, E.L. (2008). Toolkit approach to integrating library resources into the learning management system. Journal of Academic Librarianship, 34(6), 496-501.

Black, E.L. \& Blankenship, B. (2010). Linking students to library resources through the learning management system. Journal of Library Administration, 50(5), 458-467. doi:10.1080/01930826.2010.488587
Boumarafi, B. (2010). Strategies for the delivery of e-information services to support the elearning environment at the University of Sharjah. Electronic Library, 28(2), 276-285. doi:10.1108/02640471011033639

Canadian Association of Research Libraries. (2001). The e-learning e-volution in colleges and universities: A Pan-Canadian challenge. Retrieved from http://www.carlabrc.ca/projects/e_learning/brief_2001-e.html

Carlson R. \& Everett, D.R. (2000). Taking instruction online? In Proceedings of the midsouth instructional technology conference, Murfreesboro TN. Middle Tennessee State University. Retrieved from: http://frank.mtsu. edu/ itconf/proceed00/carlson.html

Colvin, J. (2008). Using widgets to embed library resources and services. Music Reference Services Quarterly, 11(3), 241-244. doi:10.1080/10588160802552274

Copeland, L. (2006). There be dragons...Learning management and library systems in Canada. IFLA Journal, 32(3), 200-208. doi:10.1177/0340035206070175

Date, D.A. \& Walavalkar, P. (2009). Technology enhanced learning: A TCS Library experience. DESIDOC Journal of Library \& Information Technology, 29(1), 49-55.

Dunn, R. \& Menchaca, F. (2009). The present is another country: Academic libraries, learning technologies, and relevance. Journal of Library Administration, 49(5), 469-479. doi:10.1080/01930820903089120

Eales, S. \& Scantlebury, N. (2007). Integrating library services and resources at the Open University. New Review of Information Networking, 13(1), 31-38. doi:10.1080/13614570701571476

Ge, X. (2010). Information-Seeking Behavior in the Digital Age: A Multidisciplinary Study of Academic Researchers. College \& Research Libraries, 71(5), 435-55.

Henk, M. (2010). Developing and implementing a Moodle-ares integration for physical and electronic reserves at a small liberal arts college. Journal of Interlibrary Loan, Document Delivery \& Electronic Reserves, 20(3), 149-158. doi:10.1080/1072303X.2010.488971

Jamtsho, S. \& Bullen, M. (2007). Distance education in Bhutan: Improving access and quality through ICT use. Distance Education, 28(2), 149-161. doi:10.1080/01587910701439217 
Jensen, L.A. (2010). Extend instruction outside the classroom: Take advantage of your learning management system. Computers in Libraries, 30(6), 76-78.

Judd, T. \& Kennedy, G. (2010). A five-year study of on-campus Internet use by undergraduate biomedical student. Computers \& Education, 55(4), 1564-1571. doi:10.1016/j.compedu.2010.06.022

Karplus, S.S. (2006). Integrating academic library resources and learning management systems: The library Blackboard site. Education Libraries, 29(1), 5-11.

Luther, J. (1998). Distance learning and the digital library, or what happens when the virtual students needs to use the virtual library in a virtual university. Educom Review, 33(4), 2226.

Maikish, A. (2006). Moodle: A Free, easy, and constructivist online learning tool. Multimedia and Internet@Schools, 13(3),2628.

Makri, S., Blandford, A., Gow, J., Rimmer, J., Warwick, C., and Buchanan, G. (2007). A library or just another information resource? A case study of users' mental models of traditional and digital libraries. Journal of the American Society for Information Science \& Technology, 58(3), 433-445. doi:10.1002/asi.20510

Menges, B. (2009). Using Moodle (open source software) with grades 3-6. School Library Monthly, 26(2), 21-22.

Najduch, J. (2009). The Association's associations: ALSC. American Libraries, 40(4), 14.

O'Brien, M. \& Wisbey, J. (2008). Building a dynamic online learning and community environment. Access, 22(3), 29-35.

Reinhart, C.J. (2008). Constructing the café university: Teaching and learning on the digital frontier. On the Horizon, 16(1), 13-33. doi:10.1108/10748120810853327

Shank, J. D., \& Dewald, N.H. (2003). Establishing our presence in courseware: Adding library services to the virtual classroom. Information Technology \& Libraries, 22(1), 38-43.

Smale, M.A. \& Regalado, M. (2009). Using Blackboard to deliver library research skills assessment. Communications in Information Literacy, 3(2), 142-157.

Thomsett-Scott, B. and Reese P.E. (2006). Changes in Library Technology and Reference Desk Statistics: Is There a Relationship? In T. Diamond \& M. Sanders (Eds.), Reference
Assessment and Evaluation (pp. 143- 165). New York, NY: Hawthorne Information Press. Williams van Rooij, S.W. (2009). Adopting opensource software applications in U.S. higher education: A cross-disciplinary review of the literature. Review of Educational Research, 79(2), 682-701.

\section{NOTES}

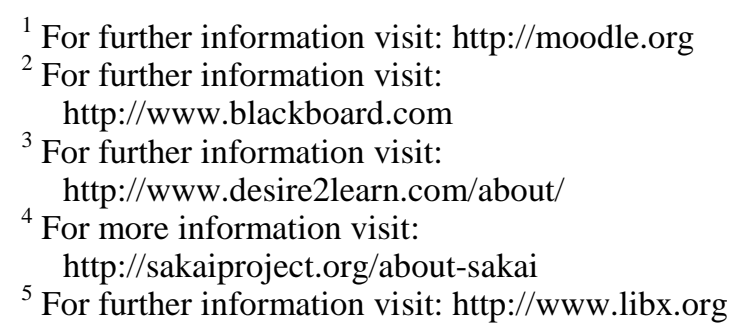

